\title{
Environmental filtering drives herb community composition and functional trait changes across an elevational gradient
}

\author{
Zihan Jiang \& Keming Ma*
}

State Key Lab of Systems Ecology, Research Center for Eco-Environmental Sciences, Chinese Academy of Sciences, CN-100085 Beijing, P.R. China

*Author for correspondence: mkm@rcees.ac.cn

\begin{abstract}
Background and aims - Under the assumption that ecologically similar species have similar functional traits, numerous studies have tried to use a trait-based approach to infer the abiotic and biotic factors that drive the variation in community composition. We used trait-based analyses to predict the responses in herb community composition to elevational change. We demonstrated the trait-environment relationships more precisely, and quantified the relative contribution of intraspecific variation and species replacement to shifts in community-level trait values across elevation.

Methods - We measured herb community, leaf functional traits, and environmental variables along an elevational gradient at Donglingshan Mountain, China. We examined the relationships between environmental variables and functional traits and analysed the variation of functional traits along the elevational gradient.

Key results - Minimum temperature (MinT) and light availability were the most important factors that shaped the herb community across elevation. Leaf hardiness and thickness were correlated strongly with MinT, while leaf mass per area, hair density, and leaf area were correlated with light availability. The trends in traits across an elevational gradient were due both to species replacement and intraspecific variation; however, the proportion of the species replacement depended on the functional traits evaluated.

Conclusions - These results allowed us to identify the major functional traits and environmental factors involved in the herb community composition along the elevational gradient and demonstrate that environmental filtering (in this case MinT and light availability) is the process that shapes both herb community composition and functional traits. Moreover, we highlighted the need for greater consideration of the role that intraspecific variation plays in changes in functional traits, which can assist us in understanding herb community composition across elevations, and also in predicting its responses to climate change.
\end{abstract}

Key words - Community composition, elevation, environmental filtering, functional traits, herb community, trait-environmental relationships.

\section{INTRODUCTION}

A central goal of plant ecology is to understand and predict the key factors that control plant species distribution and community composition (Grime 1977, Tilman 2000). One key to this goal is the observation that plants that live under the same environmental conditions often have similar morphological and physiological functional traits (Legner et al. 2014, Molinari \& D'Antonio 2014). When environmental conditions change, dominant functional traits in the community will change as the result of species replacement and intraspecific variation (Cowles 1899). This consistency suggests that we can understand the key factors that control the composition and structure of communities by studying how plant functional traits change along complex gradients (Leingärtner et al. 2014, Marteinsdóttir \& Eriksson 2014, Molinari \& D'Antonio 2014).

Herb species comprise the majority of plant diversity in forest systems and they affect nutrient cycling and energy exchange (Roberts 2004). Recently, forests have experienced climate warming, and it is important to evaluate the responses of herb communities to these changes (Naeem \& Wright 2003). The elevational gradient offering steep environmental gradients over short spatial distances can be used as a spacefor-time substitution to provide insights into the responses of herb communities to climate change (Grinnell 1924).

When we try to use a traits-based approach to predict how herb community composition changes along an elevational 
gradient, it is important to establish the precise relationships between environmental factors and functional traits, as functional traits often respond similarly to different environmental factors (Cornelissen et al. 2003). For example, lower leaf mass area (LMA), can be caused either by low temperatures or high nutrient stress (Poorter et al. 2008), while smaller leaf area (LA) may represent a functional strategy associated with low water availability or high solar radiation (Parkhurst $\&$ Loucks 1972). Moreover, along the elevational gradient, the distribution and abundance of herb species are influenced by many factors, such as temperature, soil moisture, and nutrient supply, which have been shown to correlate strongly with herb distribution (Kessler et al. 2011, Letten et al. 2013). Variation in environmental factors leads to changes in biotic interactions; for example, forest-floor light increases with elevation because temperature limits the production of overstorey-layer species, which also can shape herb communities (Barton 1993). Therefore, it is important to identify clear relationships between environmental factors and functional traits to obtain a more mechanistic understanding of the role of functional traits in community composition (Lebrija-Trejos et al. 2010).

Variations in functional traits along elevational gradients are caused by species replacement and/or intraspecific variation. Therefore, to predict the responses of plant communities to environmental change, it is necessary to assess the relative contribution of intraspecific variation and species replacement in variations in functional traits (Kichenin et al. 2013). In most previous studies, intraspecific variation has been considered to be far less important than species replacement (Albert et al. 2011, Richardson et al. 2001). However, recent studies have shown that this assumption is not always met (Lecerf \& Chauvet 2008, Messier et al. 2010), and increasing evidence has demonstrated that intraspecific variation actually plays a crucial role in community composition (Cornwell \& Ackerly 2009, Jung et al. 2010). Therefore, assessing the relative importance of species replacement and intraspecific variation is one of the steps needed to advance our understanding of community composition (Cornwell \& Ackerly 2009, Litchman et al. 2007, McGill et al. 2006, Wright et al. 2010).

In this study, we analysed the importance of environmental filtering in herb communities by linking the variation in environmental variables, community composition, and functional traits along the $750 \mathrm{~m}$ elevational gradient (1020 to $1770 \mathrm{~m}$ a.s.l.). We addressed the following questions: (1) Which key factors control herb community composition and structure change along the elevational gradient? (2) How do functional traits change along an elevational gradient? and (3) To what extent do intraspecific variation and species replacement contribute to trends in the mean trait values of a community?

\section{METHODS}

\section{Study area}

We collected data on Donglingshan Mountain, an extension of the Xiaowutaishan Mountains, $100 \mathrm{~km}$ northwest of Beijing, China, located at $40^{\circ} 00^{\prime}-40^{\circ} 03^{\prime} \mathrm{N}$ and $115^{\circ} 26^{\prime}-115^{\circ} 30^{\prime} \mathrm{E}$. The mean annual precipitation in the region is $500-650 \mathrm{~mm}$, and it has a typical warm-temperate, continental monsoon climate. The mean annual temperature is $5-10^{\circ} \mathrm{C}$. The natural vegetation consists of highly heterogeneous, warm, temperate zone, deciduous broad-leaved forest, including primarily oaks (Quercus spp.), mixed deciduous species (e.g. Tilia spp., Ulmus spp., Acer spp., Betula spp., Populus davidiana, Juglans mandshurica, and Fraxinus rhyncho-phylla). There are also some conifers (Pinus tabuliformis, Platycladus orientalis) and shrubs (e.g. Prunus spp., Vitex negundo var. heterophylla, etc.).

\section{Sampling methods}

We studied herb communities on a $750 \mathrm{~m}$ elevational gradient, from 1020 to $1770 \mathrm{~m}$ a.s.l. We chose this range because it overlaps completely with the distribution range of Quercus liaotungensis in the study area: below $1000 \mathrm{~m}$ a.s.l., the natural forest has disappeared due to human activity, while the timberline occurs at approximately $1770 \mathrm{~m}$ a.s.l. We surveyed ten transects established from the base to the top of every western slope in the study area to compose a continuous elevational gradient. The environmental conditions in each transect were similar: orientation (west-facing: $250-280^{\circ}$ ), slope $\left(29-41^{\circ}\right)$, soil (eutric cambisol). Each transect was $10 \mathrm{~m}$ in width, and the length ranged from 80 to $200 \mathrm{~m}$, depending on the altitude range and degree of each slope. The sum of the length of ten transects was $1,190 \mathrm{~m}$, and we divided them into 119 plots of $10 \times 10 \mathrm{~m}$ each. Within each plot, three subplots $(1 \times 1 \mathrm{~m})$ were selected randomly for the inventory of herbaceous vegetation; richness was calculated as the number of species recorded in each plot, while abundance was the exact number of individuals.

The functional traits we selected corresponded to those measured in past studies (Cornelissen et al. 2003) because they have shown significant responses to particular environmental changes. Trait data measurements were taken between July and August, 2013. Within transects, we selected thirty plots at elevational intervals of $25 \mathrm{~m}$ (from 1020 to $1750 \mathrm{~m}$ a.s.l.). Within each plot, three subplots $(1 \times 1 \mathrm{~m})$ were selected randomly for an inventory of the herb species' functional traits. For each species in each subplot, leaves were collected from one representative individual; hardened leaves were sampled when possible to exclude the strong effect of herbivores and pathogens. We quantified LMA and leaf nitrogen content per area $\left(\mathrm{N}_{\text {area }}\right)$ five times (YARIOELIII Elementar, Germen) per individual. We measured LA at least once per individual (WinFOLIA Basic 2004a, REGENT Instruments Inc., Australia), and we measured leaf hardness (LH) three times per individual (Shore Durometer, China); leaf thickness (LT) was measured three times from the leaf base to tip (Microcalliper, China) per individual (for details, see Cornelissen 2003). We used a 5-class division to quantify hair density (Kluge \& Kessler 2011), because this trait is rather subjective.

\section{Environmental data}

Temperature was collected at each transect from May 2011 to May 2012 using a total of 30 Microdaq data-loggers HoboPro RH/Temp. In each plot selected for the collection 
of functional trait data, we established one data-logger $10 \mathrm{~cm}$ below ground: temperature data was collected every $30 \mathrm{~min}$.

For each subplot, light availability was measured once in July-August 2010, when the overstorey-layer species had finished their leaf expansion. Measurement was made with a digital camera (Nikon Coolpix 995) with a fish-eye lens held horizontally directly above the herb layer cover at a height of $30 \mathrm{~cm}$. Because direct radiation could influence the measurements of relative differences in radiation negatively, the measurements were taken mostly between 7 and 9 a.m. on cloudy days. Photographs were analysed subsequently using Winphot 5 (Ter Steege 1996) to calculate the total site factor (TSF), which was measured as the proportion of solar radiation in a subplot relative to that in an open area.

We used a hammer-driven soil core sampler $5 \mathrm{~cm}$ in diameter to obtain three soil profiles at a depth of $0-30 \mathrm{~cm}$ in each plot. Three replicate samples were homogenized by hand after large, live plant material (roots/shoots), and pebbles in each sample were separated by soil sieve (mesh size $=2 \mathrm{~mm}$ ) and discarded. The samples were then air-dried and soil properties were measured. The parameters of soil properties included soil organic matter, soil nitrogen availability (soil N), phosphorus availability (soil P), potassium availability (soil $\mathrm{K}$ ), $\mathrm{pH}$, and soil moisture. Soil organic matter content was measured by the $\mathrm{K}_{2} \mathrm{Cr}_{2} \mathrm{O}_{7}$ titration method after digestion (Nelson \& Sommers 1974), and soil N was measured using the semimicro Kjeldahl method (Bradstreet 2013). Soil P was measured by V-Mo colorimetry, and soil K was resolved by a flame photometer (Bao 2000). Soil moisture was measured (Moisture Meter HH2, Delta-T Devices Ltd, UK) at six locations (three times/location) in each plot and then averaged. Soil $\mathrm{pH}$ was measured in a 1:2.5 (v/v) soil:water suspension with a digital $\mathrm{pH}$ meter (PHS-3C, Shanghai Lida Instrument Company).

\section{Analyses}

We computed maximum temperature (MaxT: calculated as daily maximum temperature over a one-year period), minimum temperature (MinT: calculated as daily minimum temperature over a one-year period), mean annual temperature (MAT: calculated as mean daily temperature over a one-year period) and temperature variability (TV: calculated as MaxT minus MinT), as they have been shown to have great explanatory power for herb community composition (McCain 2007, Letten et al. 2013, Li et al. 2010). To understand how environment changes along elevational gradients, we fitted single-predictor generalized linear models (GLM) for environmental variables as quadratic and linear functions of elevation. We emphasize that our estimates of temperature variation may be lower than the true values because $10 \mathrm{~cm}$ below the surface might be too deep for accurate temperature measurement. However, we are confident that this method did not distort the main elevational pattern in temperature because any underestimation was likely to be constant among the plots.

To identify the primary factors that control the community composition along the elevational gradient, canonical correspondence analysis (CCA) was performed to assess the relationships between herb community composition and en- vironmental variables. Environmental variables were used to evaluate the response of species abundance to environmental gradients. Variables (except soil $\mathrm{pH})$ were $\log (\mathrm{x}+1)$ transformed prior to analysis to meet the assumptions of normality and equal variance. A variance inflation factor (VIF) was used to test whether particular environmental variables were inter-correlated strongly with others in our study; the set of environmental variables with a VIF lower than 10 was used in further analyses (MAT was removed) (Obolewski et al. 2014). A Monte Carlo permutation test (5000 randomizations) was applied to test the significance of each variable at $p<0.05$ (soil moisture, soil K, soil organic matter, MaxT and TV were removed). We then used the set of independent and significant environmental variables to perform the final CCA.

To identify the primary functional traits that control community composition along an elevational gradient, we performed another CCA to assess the relationships between functional traits and community composition. These variables were also $\log (\mathrm{x}+1)$ transformed prior to analysis to meet the assumptions of normality and equal, and the set of functional traits with a VIF lower than 10 was used in further analyses. Again, a Monte Carlo permutation test 5,000 randomizations) was applied to test the significance of each variable at $p<0.05$, and we used the set of independent and significant functional traits to run the final CCA. Functional traits were based on community weighted means (CWM) of the traits.

To relate patterns of environmental factors and functional traits along an elevational gradient, CWM-RDA was performed based on ordinations of two matrices: environmental variables $\times$ plots and plots $\times$ traits. CWM-RDA has been referred to as a powerful tool in the study of relationships between traits and environment (Kleyer et al. 2012). It is a multivariate technique that relates functional traits to environmental factors, in which CWM represents community weighted means of traits, and RDA represents redundancy analysis. First, environmental variables (except soil $\mathrm{pH}$ ) were $\log (\mathrm{x}+1)$ transformed prior to analysis to meet the assumptions of normality and equal variance, then a RDA based on environmental variables $\times$ plots and plots $\times$ traits was performed. Because the plots we selected to collect traits data were in different transects, this potentially calls into question whether or not the transects could be combined for data analysis. We tested the validity of considering the ten transects as one by conducting a detrended correspondence analysis. The test showed that functional traits turnover was not elevated significantly at the transition between transects (see electronic appendix $1 \&$ fig. 1). This result suggest that the transects can be combined for traits analysis.

To quantify the relative contribution of species replacement and intraspecific variation to the shift in weighted and non-weighted community-level traits values along the elevational gradient, we calculated 'specific' community-level values by using species traits values as measured in that plot (which includes the contribution of species replacement and intraspecific variation). We then calculated 'fixed' CWM by using species means throughout the plot along the elevational gradient (includes only the contribution of species replacement). Next, we performed linear regression analyses, with 
two types of community-level trait values as response variables, and elevation as an explanatory variable. We calculated the slope of the relationship between functional traits and elevational gradient, and considered that the difference in the slope between two types of community-level functional traits represented the contribution of intraspecific variation. Moreover, to assess how dissimilar the species composition was in different plots along the elevational gradient, we performed a Pearson correlation analysis to evaluate relationships between species dissimilarity and elevational distance. Pairwise species dissimilarity was calculated based on Jaccard's coefficient method (Jaccard 1908). All analyses were performed in $\mathrm{R}$ version 2.01 (R Core Team 2012), while the calculations of CWM-RDA were conducted with package RDA (Hastie \& Tibshirani 2009).

\section{RESULTS}

We collected 95 herb species from 24 families; the most relevant in terms of richness were Asteraceae (28), Liliaceae (13), and Ranunculaceae (11). The three most common species were Dendranthema chanetii (Levl) Shih, Saussurea nivea Turcz, and Thalictrum minus L., which were encountered in $65 \%, 56 \%$, and $55 \%$ of the subplots, respectively. Both richness and abundance increased linearly with elevation (richness: $\mathrm{r}=0.65, p<0.01$; abundance: $\mathrm{r}=0.76$, $p<0.01)$.

MinT, MaxT, MAT, TSF and soil N exhibited significant linear relationships with elevation (table 1), and all of these variables decreased with elevation except TSF, which was correlated positively with elevation. TV exhibited a signifi- cant unimodal relationship with elevation, with a maximum at approximately $1400 \mathrm{~m}$ a.s.l, and a decline at higher and lower elevations. Other environmental variables did not exhibit significant relationships with elevation.

There were strong trends in CWM for plots across the elevational gradient. We observed that LH, HD, LT, and LMA all changed positively with increasing elevation (fig. 1). LH and LMA increased rapidly, while HD and LT increased more gradually. We found no relationship between elevation and $\mathrm{N}_{\text {area }}$ or LA.

Results of the CCA based on environmental variables are shown in fig. 2. The eigenvalues of the first and second axes were 0.33 and 0.19 , respectively; the first two axes explained $50 \%$ of the total variance in the herb community composition data. The species-environment correlations for the first and second axes were 0.97 and 0.93 , respectively. Monte Carlo tests were significant for all axes, indicating that the ordination result was credible. The first axis was correlated most positively with TSF $(r=0.82)$, but was correlated negatively with MinT $(r=-0.67)$, while the second axis was correlated most positively with soil $\mathrm{pH}(\mathrm{r}=0.42)$ and most negatively with soil $\mathrm{N}(\mathrm{r}=-0.73)$.

Results of the CCA based on functional traits are shown in fig. 3. The eigenvalues of the first and second axes were 0.61 and 0.17 , respectively, and the first two axes explained $70 \%$ of the total variance in the herb community composition data. The species-traits correlations for the first and second axes were 0.90 and 0.87 , respectively. Monte Carlo tests were significant for all axes, indicating that the ordination result was credible. The first axis was correlated most nega-
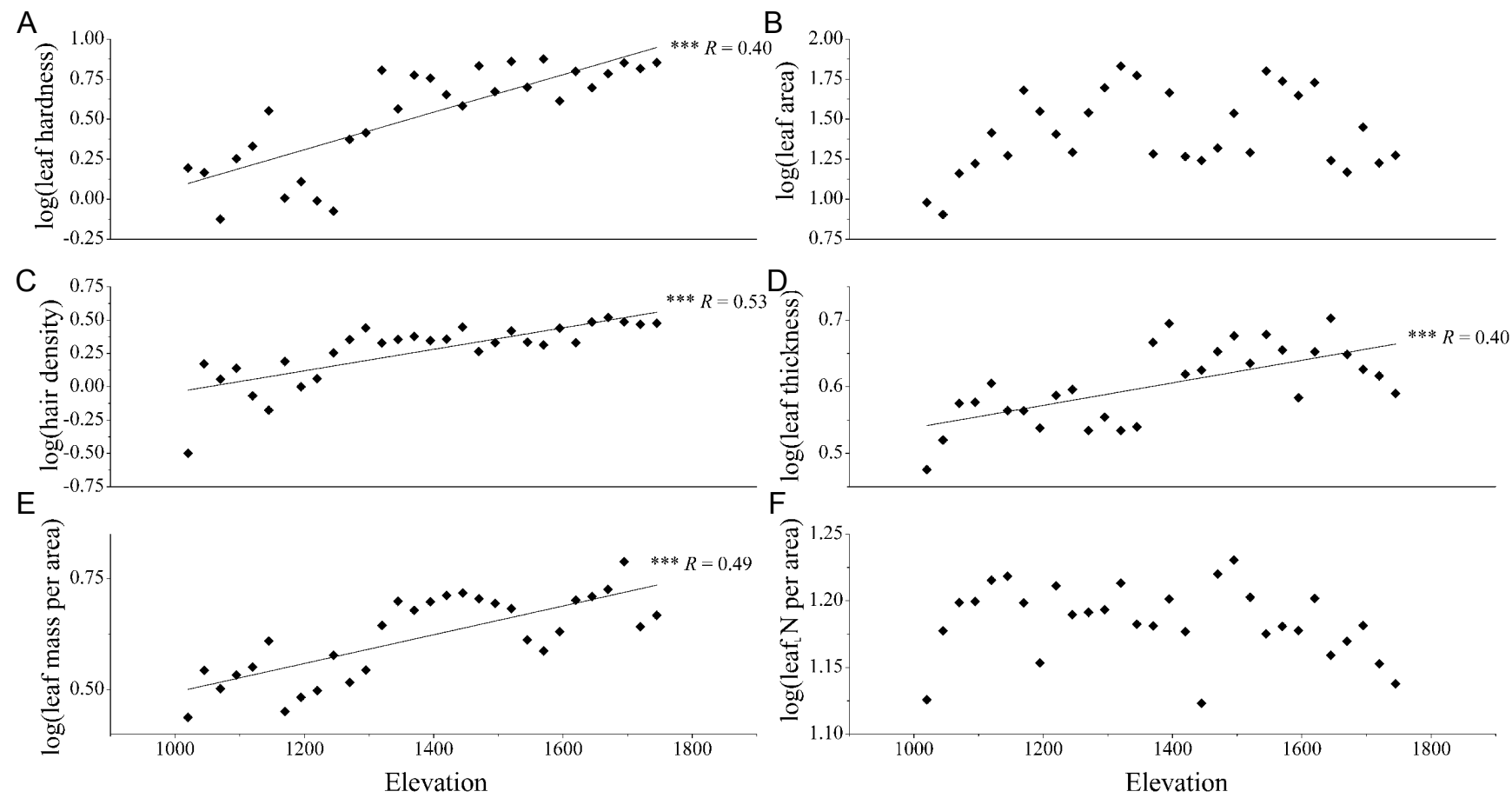

Figure 1 - Relationships between elevation and: A, leaf hardness (LH); B, leaf area (LA); C, hair density (HD); D, leaf thickness (LT); E, leaf mass/area (LMA); F, leaf $\mathrm{N}$ concentration/area for herb communities, with the functional traits based on community weighted traits mean. Adj. $R$-squared $\left(R^{2}\right)$ and significance values are shown $\left({ }^{*} p<0.1,{ }^{*} p<0.05,{ }^{* *} p<0.01,{ }^{* * *} p<0.001\right)$. 
tively with LH $(\mathrm{r}=-0.71)$, but was correlated positively with $\mathrm{N}_{\text {area }}(\mathrm{r}=0.24)$, while the second axis was correlated most positively with LA $(r=0.74)$, followed by LT $(r=0.63)$.

We conducted further analyses to examine the relationship between functional traits and environmental factors. The first two axes of the CWM-RDA explained $44.13 \%$ and $11.30 \%$, respectively, of the total variance in the matrix that related the environmental variables to the functional traits (fig. 4). The Monte Carlo test showed that there were significant relationships between functional traits and environmental variables ( $p<0.001,1000$ permutations). The first CWMRDA axis correlated most negatively with MinT $(r=-0.76)$, but correlated positively with TSF $(\mathrm{r}=0.78)$. The second axis was correlated most negatively with soil $\mathrm{N}(\mathrm{r}=0.49)$, and most positively with soil $\mathrm{P}(\mathrm{r}=0.55)$. LT and LH had negative relationships with MinT. LMA and HD were associated positively with the TSF, while LA was associated negatively with it. Finally, $\mathrm{N}_{\text {area }}$ was associated positively with soil $\mathrm{N}$.

The trends in functional traits values across the elevational gradients were due to intraspecific variation and/or species replacement. Using data for LH, LT, and LMA, we were able to partition the strength of the pattern for each of these drivers (fig. 5). We did not use $\mathrm{N}_{\text {area }}$ and HD because we used a class division to quantify $\mathrm{HD}$, and it is difficult to quantify the contribution of intraspecific variation and $\mathrm{N}_{\text {ree }}$, which exhibited insignificant elevational patterns. For LH, $29 \%$ of the slope of the plot mean response could be attributed to intraspecific variation; the remaining $71 \%$ was due to species replacement (species replacement alone: $R=0.40, p<0.001$;
Table 1 - Relationships between environmental variables and elevation, using generalized linear models.

We linked environmental variables and elevation by linear and unimodal models, $\mathrm{ns}=$ explanatory variables non-significant with response variables. Direction of relationship indicated by + (positive relationship) or - (negative relationship), d.f. represents degrees of freedom. Adj. $R$-squared $\left(R^{2}\right)$ and significance values are shown $\left({ }^{*} p<0.05,{ }^{* *} p<0.01, * * * p<0.001\right)$. MinT, minimum temperature during a year; MaxT, maximum temperature during a year; MAT, mean annual temperature; TV, temperature variability; TSF, total site factor; soil N, soil nitrogen availability; soil P, soil phosphorus availability; soil K, soil potassium availability; SM, soil moisture; SOM, soil organic matter.

\begin{tabular}{cccc}
\hline $\begin{array}{c}\text { Environmental } \\
\text { Factor }\end{array}$ & df & $\begin{array}{c}\mathrm{R}^{2} \text { of linear } \\
\text { model }\end{array}$ & $\begin{array}{c}\mathrm{R}^{2} \text { of unimodal } \\
\text { model }\end{array}$ \\
\hline MinT & 29 & $-0.34^{* *}$ & $\mathrm{~ns}$ \\
MaxT & 29 & $-0.45^{* *}$ & $\mathrm{~ns}$ \\
MAT & 29 & $-0.31^{* *}$ & $\mathrm{~ns}$ \\
TV & 29 & $\mathrm{~ns}$ & $0.22^{* *}$ \\
TSF & 119 & $+0.42^{* *}$ & $\mathrm{~ns}$ \\
Soil N & 119 & $-0.21^{*}$ & $\mathrm{~ns}$ \\
Soil P & 119 & $\mathrm{~ns}$ & $\mathrm{~ns}$ \\
Soil pH & 119 & $\mathrm{~ns}$ & $\mathrm{~ns}$ \\
Soil K & 119 & $\mathrm{~ns}$ & $\mathrm{~ns}$ \\
SM & 119 & $\mathrm{~ns}$ & $\mathrm{~ns}$ \\
SOM & 119 & $\mathrm{~ns}$ & $\mathrm{~ns}$ \\
\hline
\end{tabular}

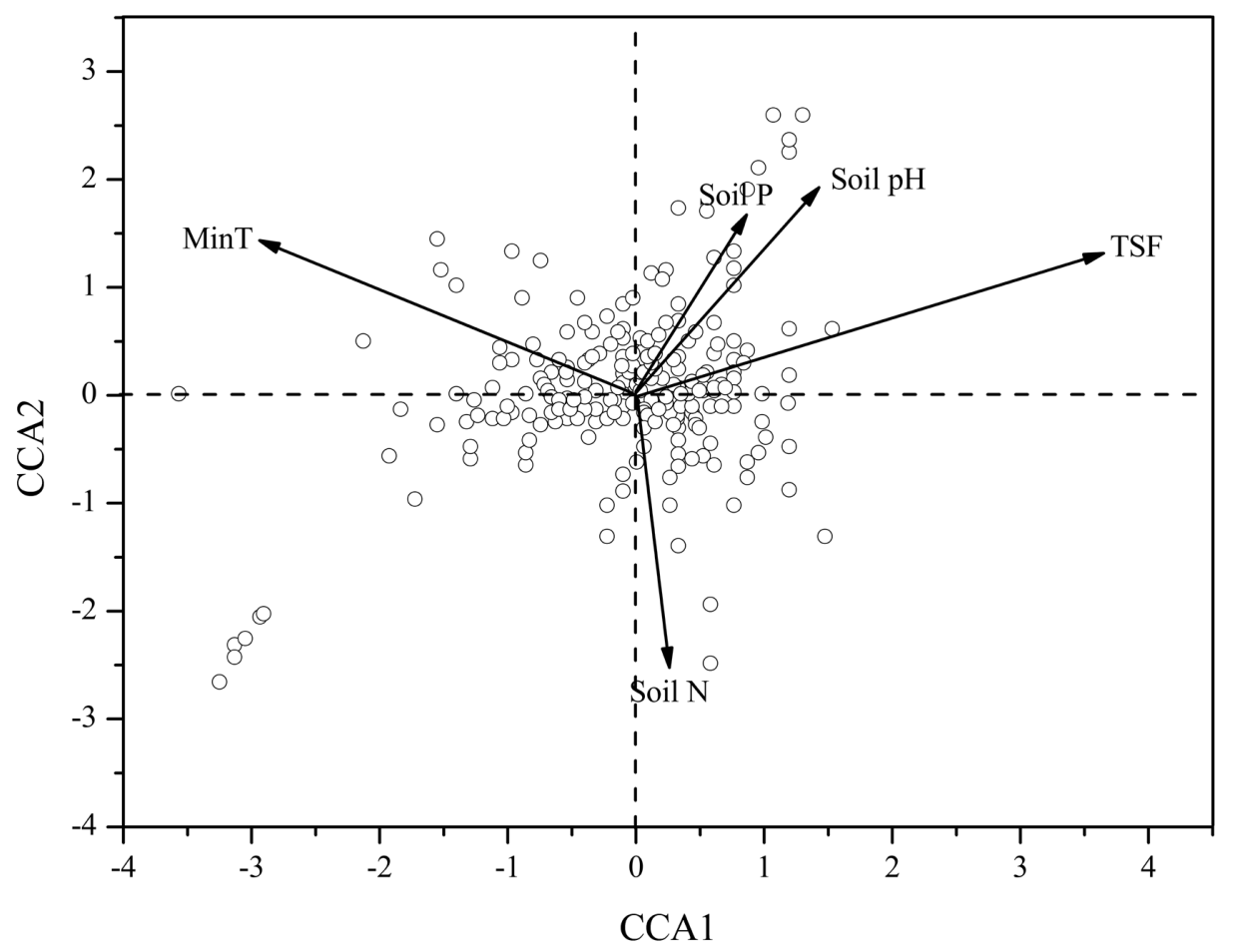

Figure 2 - Canonical correspondence analysis of ordination plots for herb species and environmental variables. Environmental variables $=$ lines with arrows; herb species = open circles. Data from 119 plots in herb community we investigated. Abbreviations are explained in the caption of table 1 . 
Pl. Ecol. Evol. 148 (3), 2015

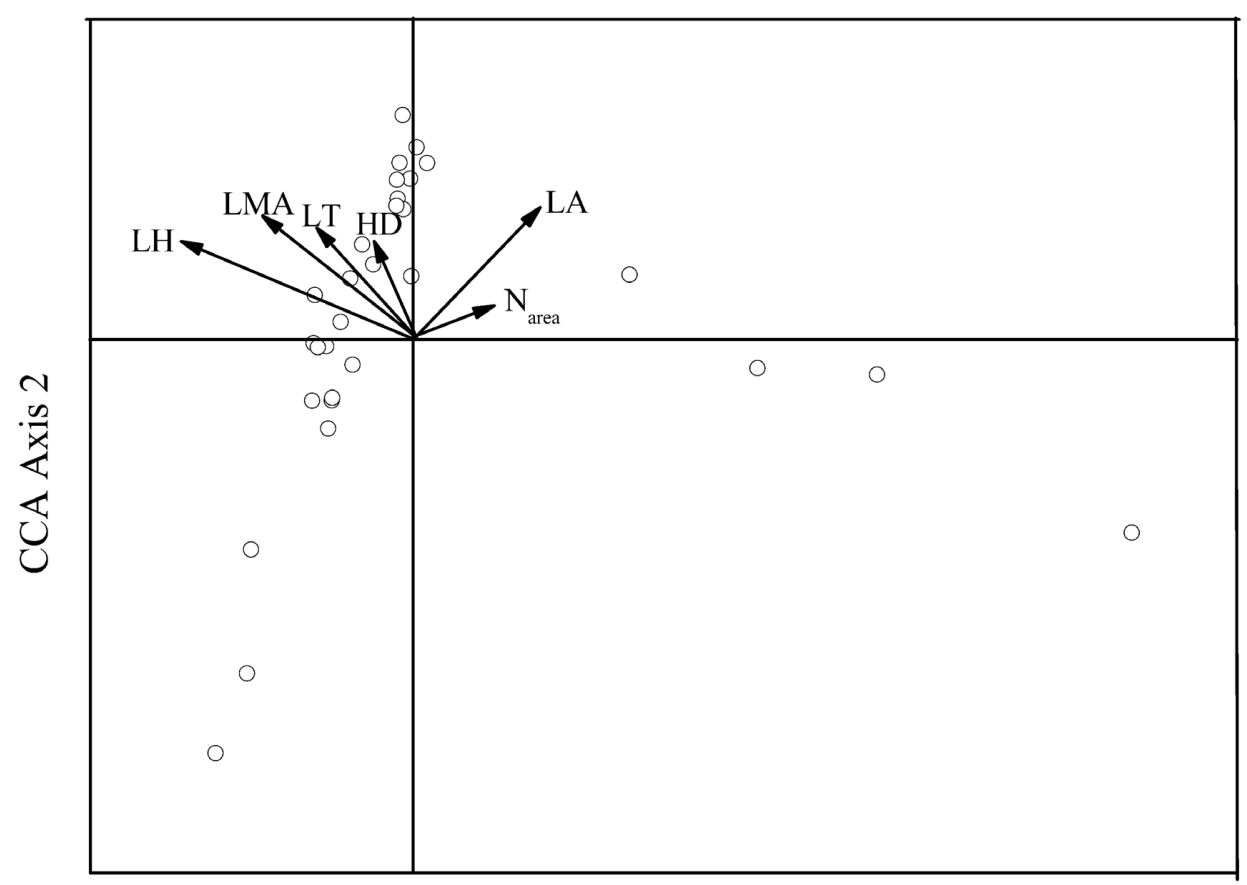

CCA Axis 1

Figure 3 - Canonical correspondence analysis of ordination plots for herb species and functional traits. Functional traits = lines with arrows; herb species = open circles. LH represents leaf hardness, LMA represents leaf mass/area, LT represents leaf thickness, HD represents hair density, LA represents leaf area, $\mathrm{N}_{\text {area }}$ represents leaf nitrogen content/area. Data from 30 plots in which we collected functional traits.

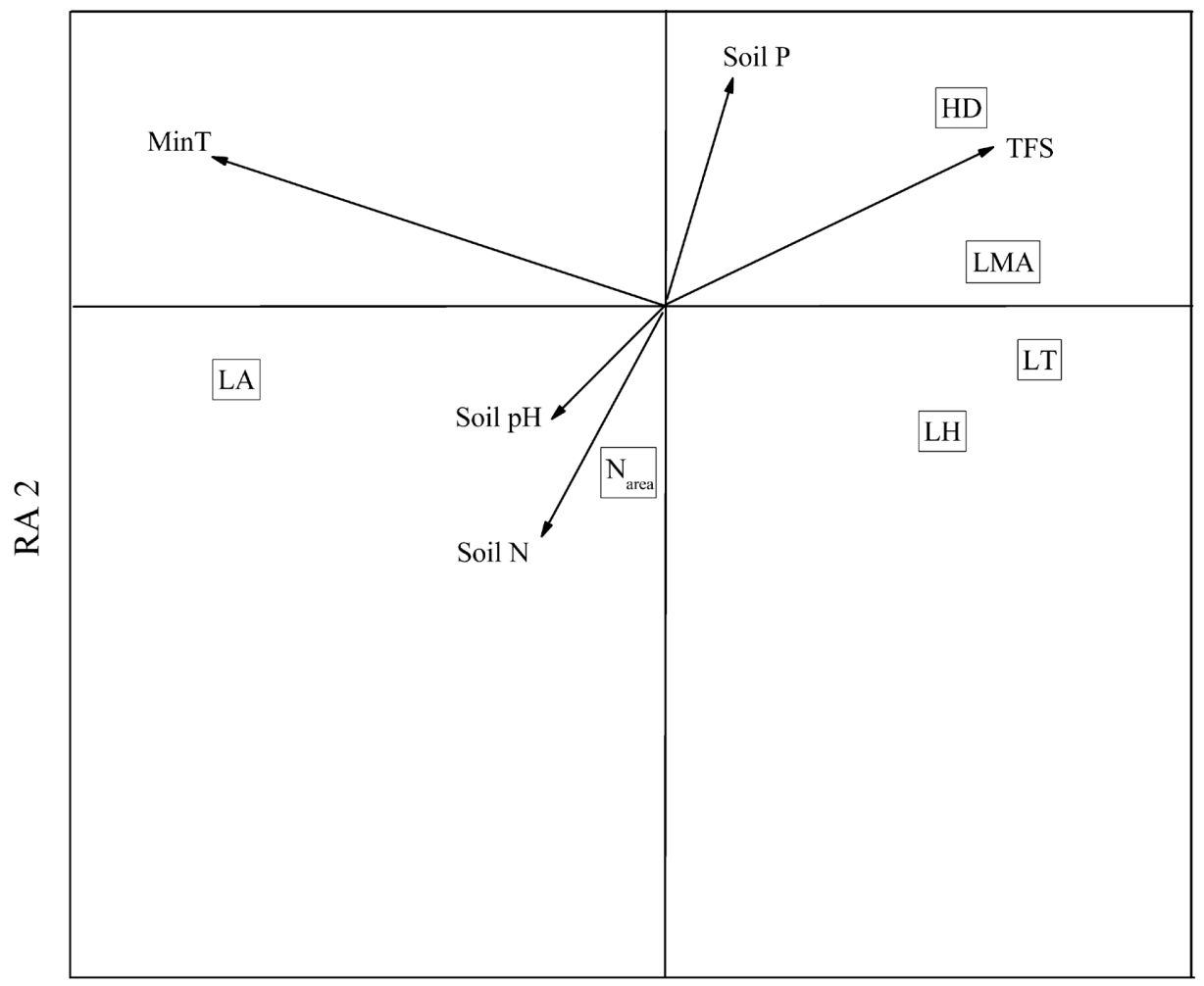

RA 1

Figure 4 - Redundancy analysis of ordination plots for environmental variables and functional traits (based on community-weighted trait means). Environmental variables = lines with arrows; functional traits = square frame. Data from 30 plots in which we collected functional traits. 

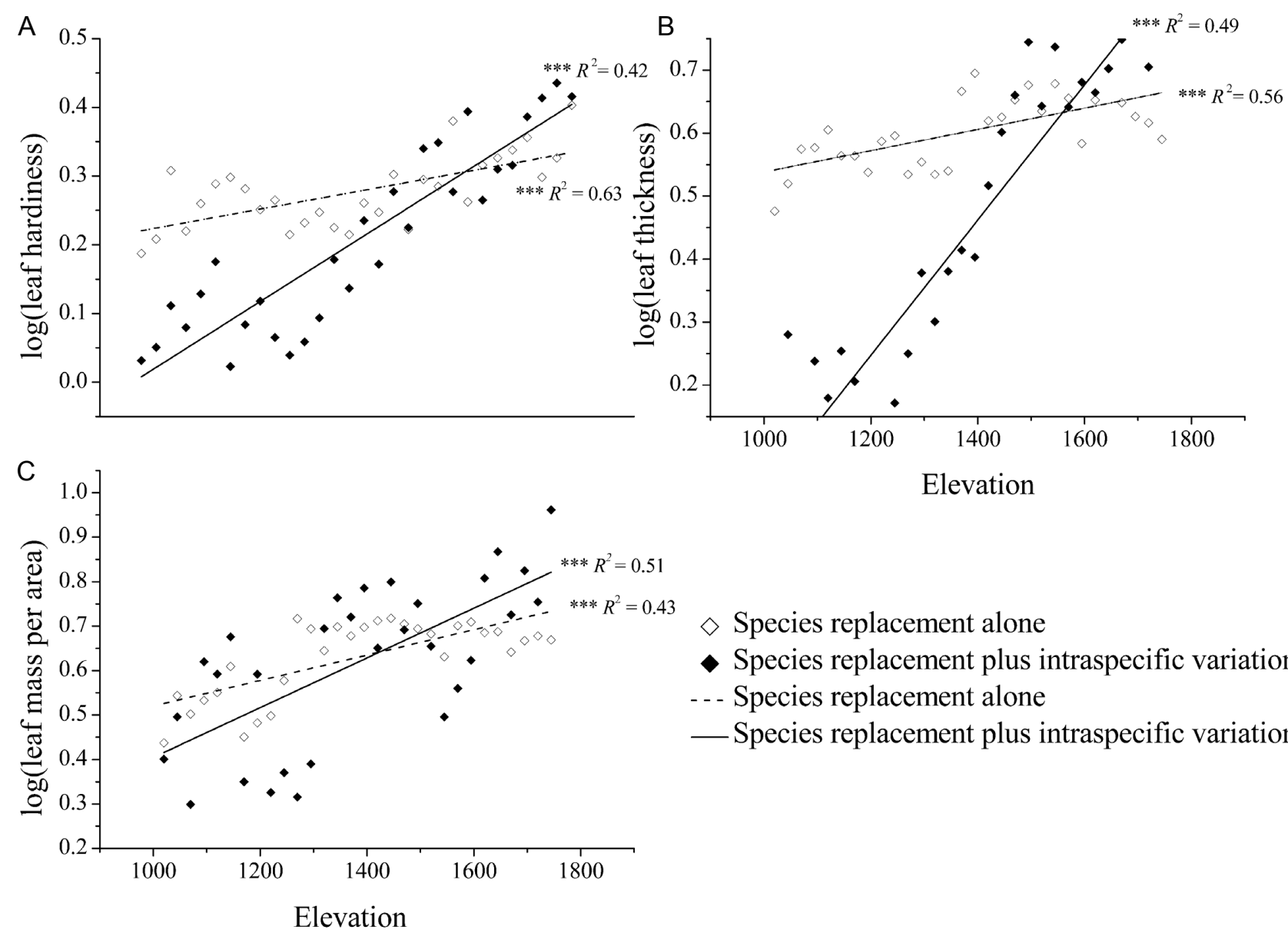

Elevation

$\diamond$ Species replacement alone

- Species replacement plus intraspecific variations - - Species replacement alone

— Species replacement plus intraspecific variations

Figure 5 - The community-level trait-elevation relationship (weighted by species relative abundance) with only species replacement considered (open diamond and dashed line), and with species replacement plus intraspecific variation (solid diamond and solid line). Panel A shows leaf hardiness, panel B shows leaf thickness, panel C shows leaf mass per area.

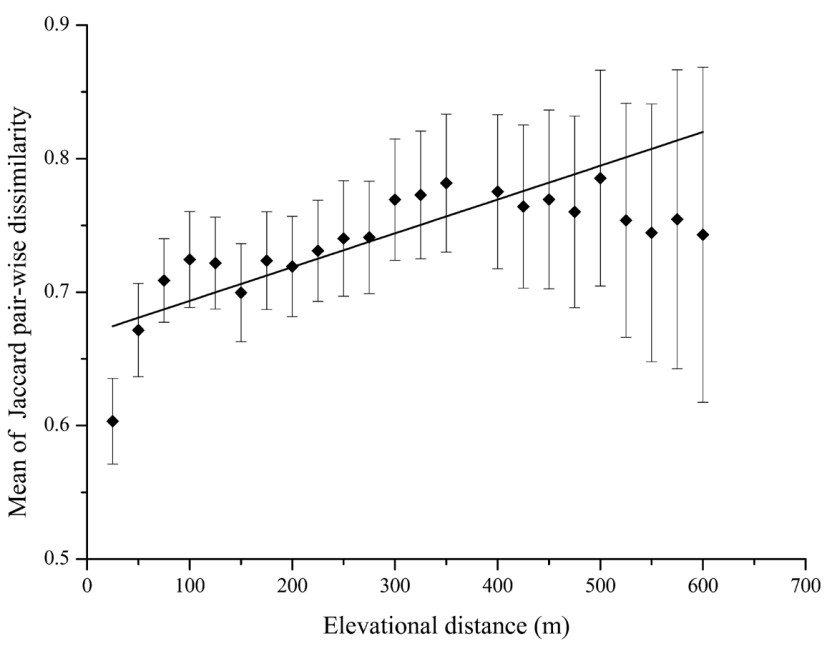

Figure 6 - Relationships between elevational distance and species dissimilarity. Standard error and adj. $R$-squared $\left(R^{2}\right)$, significance levels are as above. species replacement plus intraspecific variation: $R=0.90$, $p<0.001$ ). For LT, $16 \%$ of the slope of the plot mean response could be attributed to intraspecific variation, while the remaining $84 \%$ was due to species replacement (species replacement alone: $R=0.43, p<0.001$; species replacement plus intraspecific variation: $R=0.89, p<0.001)$. For LMA, $51 \%$ of the slope of the plot mean was due to intraspecific variation, and $49 \%$ was due to species replacement (species replacement alone: $R=0.43, p<0.001$; species replacement plus intraspecific variation: $R=0.49, p<0.001$. The nonweighted analysis yielded very similar patterns; see electronic appendix $1 \&$ fig. 2). The mean of pairwise species dissimilarity increased significantly with elevational distance (fig. 6); the minimum was 0.60 at $25 \mathrm{~m}$, and the maximum was 0.78 at $500 \mathrm{~m}$.

\section{DISCUSSION}

Our results revealed that: (1) MinT and light availability are the most important environmental factors that drive the 
changes in community composition and functional traits along an elevational gradient, while soil nutrient supply appears to be secondary to their effects; (2) different functional traits derived from different envrionmental variables; and (3) the contribution of species replacement are greater than that of intraspecific variation, but the proportion of species replacement depends on the functional traits evaluated, consistent with our expectation that species replacement and intraspecific variation act in concert to produce elevational patterns in functional traits.

Because MinT acts as a key environmental filter that drives changes in herb communities along elevational gradients, we would expect that elevational comparisons of MinT make sense in the context of physiological stress (Körner 2007). The proportion of herb species and individuals with thicker and harder leaves increased in the herb community along the elevational gradient, a phenomenon that can be explained by the fact that freezing temperatures occur more frequently at higher elevations. At low temperatures, lipid membranes can solidify (Atkinson et al. 2010) and ice crystals can rupture cell membranes (Renaut et al. 2004). For herbs to survive freezing temperatures, thicker and harder leaves are necessary adaptations, as such leaves can better protect assimilatory tissue from low temperature damage (Cornelissen et al. 2003, Palta \& Li 1979), and contribute to longer leaf lifespan (Houter \& Pons 2014). For species that persist at higher elevations, a greater investment of carbon in structural protection is also beneficial. Moreover, decreased mean temperatures limit the growth of trees, which may lead to increased light levels at the forest floor. Therefore, along the elevational gradient, light levels progress from shady to sunny.

We suggest that the effects of light availability are multifaceted; on the one hand, adequate light is necessary to guarantee carbon gain, and in the shady, relatively warm conditions at low elevations, the herb communities were dominated by species with larger, thinner leaves (fig. 2); these leaves enhance light interception per leaf area, which in turn increases the net photosynthetic rate under shaded conditions (Falster \& Westoby 2003). On the other hand, plant species may be affected adversely by high solar radiation, and therefore, an increased abundance of herb species with high hair density should be taken as evidence of the expected increase in defensive functional traits for protection from higher levels of ultraviolet radiation (Cornelissen et al. 2003). Moreover, high solar radiation leads to reductions in net photosynthesis that parallel the effects of soil drought (Shirke \& Pathre 2004). High irradiance results in an incremental increase in the leaf-to-air vapour pressure deficit (VDP), which increases water stress, even if there is adequate soil water available (Lebrija-Trejos et al. 2010). This, in turn, may affect photosynthesis adversely (Lawlor $\&$ Cornic 2002). Thus, the proportion of herb species and individuals with higher LMA and smaller leaves increased in the herb community along the elevational gradient. This phenomenon can be explained by the fact that higher LMA contributes to protection from desiccation (Mooney \& Dunn 1970), and smaller leaf area helps maintain higher photosynthetic water-use efficiency under high irradiance (Parkhurst $\&$ Loucks 1972). These functional traits imply further that maintaining favourable photosynthesis under conditions of high solar radiation is important for herb species to persist at higher elevations.

Analyses of functional traits at the community level revealed that herb species living on the elevational gradient studied had different sets of functional traits that revealed their varied adaptive strategies. While shade-tolerant species are favoured by the environment at lower elevations, where they benefit from the relative warmth, low temperature-tolerant species are favoured by environments at higher elevations, where they benefit from greater light availability.

The leaf $\mathrm{N}$ content of herb species tended to vary significantly with soil $\mathrm{N}$ availability, which may be explained by the fact that herb species have different optimum leaf $\mathrm{N}$ concentrations in different environmental contexts. Other soil nutrients showed no relationship with functional traits, probably because we missed some important functional traits that exhibit better responses to variations in soil nutrients (e.g. belowground functional traits or leaf P content). Another probable interpretation of this phenomenon is that soil nutrients should be a less important factor in restricting the range of trait values: many studies have shown that there is no relationship between leaf $\mathrm{N}$ content and soil $\mathrm{N}$ availability, because high-elevation plants inhibit the dilution of $\mathrm{N}$ and other nutrients in leaf tissue (Körner 1989), which results in high-elevation plants having higher leaf $\mathrm{N}$ content. In this study, soil moisture did not have a significant effect on herb community composition. However, we cannot rule out the influence of soil moisture (Kessler 2001), as it is important to recognize that it reinforces or alleviates temperature stress (Bhattarai et al. 2004).

The rapid shift in the functional traits of herb communities can be explained by a combination of intraspecific variation and species replacement, and in this study, species replacement played a much larger role. Plant species that showed relatively higher levels of intraspecific variation along such elevational gradients should have a greater resistance to climatic change (Matesanz et al. 2010, Rapp et al. 2012). However, if the magnitude of the temperature change is sufficiently severe, species replacement will occur to a greater extent (Ackerly 2003).

The relative contribution of intraspecific variation and species replacement on variation in functional traits can differ among traits. It is noteworthy that intraspecific variation also is an important driver of community structure and composition, such that community responses to environmental change cannot be captured entirely by approaches based only on mean traits values.

In this study, herb community composition was predicted best by temperature and light availability. LMA, LA and HD were linked to light conditions, while LH and LT were important functional traits for tolerance of low temperatures. Further, unmeasured functional traits, for example, traits related to the plant's water status or soil nutrients, also could play roles in the determination of community composition. Functional traits that change and are driven by species replacement and/or intraspecific variation can contribute to the overall responses of an herb community to environmental change. Our results indicated that, along an elevational 
gradient, the interaction between the effects that the environmental conditions (temperature and light) have on community composition and the ecotypes adopted is especially important. By including environmental measurements, our approach allowed us to identify the specific functional traits and environmental factors that are responsible for major ecological responses in an ecosystem, and we confirmed that environmental filtering is a fundamental and on-going process in community composition.

\section{SUPPLEMENTARY DATA}

Supplementary data are available in pdf at Plant Ecology and Evolution, Supplementary Data Site (http://www.ingentaconnect.com/content/botbel/plecevo/supp-data) and consist of: (1) detrended correspondence analysis of ordination plots for functional traits (based on community-weighted trait means); and (2) the community-level (non-weighted by species relative abundance) trait-elevation relationships with only species replacement considered, and with species replacement plus intraspecific variation.

\section{ACKNOWLEDGEMENTS}

This work was supported by National Natural Science Foundation of China (31470481) and the State Key Laboratory of Urban and Regional Ecology of China (SKLURE2013-1-02).

\section{REFERENCES}

Ackerly D.D. (2003) Community assembly, niche conservatism, and adaptive evolution in changing environments. International Journal of Plant Sciences 164: S165-S184. http://dx.doi. org/10.1086/368401

Albert C.H., Grassein F., Schurr F.M., Vieilledent G., Violle C. (2011) When and how should intraspecific variability be considered in trait-based plant ecology? Perspectives in Plant Ecology, Evolution and Systematics 13: 217-225. http://dx.doi. org/10.1016/j.ppees.2011.04.003

Atkinson L.J., Campbell C.D., Zaragoza-Castells J., Hurry V., Atkin O.K. (2010) Impact of growth temperature on scaling relationships linking photosynthetic metabolism to leaf functional traits. Functional Ecology 24: 1181-1191. http://dx.doi. org/10.1111/j.1365-2435.2010.01758.x

Bao S. (2000) Analysis method of soil agricultural chemistry. Beijing, China Agricultural Press.

Barton A.M. (1993) Factors controlling plant distributions: drought, competition, and fire in montane pines in Arizona. Ecological Monographs 63: 367-397. http://dx.doi.org/10.2307/2937151

Bhattarai K.R., Vetaas O.R., Grytnes J.A. (2004) Fern species richness along a central Himalayan elevational gradient, Nepal. Journal of Biogeography 31: 389-400. http://dx.doi. org/10.1046/j.0305-0270.2003.01013.x

Bradstreet R.B. (2013) The Kjeldahl method for organic nitrogen. New York, Elsevier Press.

Cornelissen J., Lavorel S., Garnier E., Diaz S., Buchmann N., Gurvich D., Reich P., Ter Steege H., Morgan H., Van Der Heijden M. (2003) A handbook of protocols for standardised and easy measurement of plant functional traits worldwide. Australian Journal of Botany 51: 335-380. http://dx.doi.org/10.1071/ BT02124
Cornwell W.K., Ackerly D.D. (2009) Community assembly and shifts in plant trait distributions across an environmental gradient in coastal California. Ecological Monographs 79: 109-126. http://dx.doi.org/10.1890/07-1134.1

Cowles H.C. (1899) The ecological relations of the vegetation of the sand dunes of Lake Michigan. Part I.-Geographical relations of the dune floras. Botanical Gazette 27: 95-117.

Falster D.S., Westoby M. (2003) Leaf size and angle vary widely across species: what consequences for light interception? New Phytologist 158: 509-525. http://dx.doi.org/10.1046/j.14698137.2003.00765.x

Grime J. (1977) Evidence for the existence of three primary strategies in plants and its relevance to ecological and evolutionary theory. The American Naturalist 111: 1169-1194.

Grinnell J. (1924) Geography and evolution. Ecology 5: 225-229. http://dx.doi.org/10.2307/1929447

Hastie Y., Tibshirani R. (2009) rda: shrunken centroids regularized discriminant analysis. R package version 1. Available at http:// CRAN.R-project.org/package=rda [accessed xx xxx 201x].

Houter N.C., Pons T.L. (2014) Gap effects on leaf traits of tropical rainforest trees differing in juvenile light requirement. Oecologia 175: 37-50. http://dx.doi.org/10.1007/s00442-014-2887-9

Jaccard P. (1908) Nouvelles recherches sur la distribution florale. Bulletin de la Société Vaudoise des Sciences Naturelles 44: 223-270. http://dx.doi.org/10.5169/seals-268384

Jung V., Violle C., Mondy C., Hoffmann L., Muller S. (2010) Intraspecific variability and trait-based community assembly. Journal of Ecology 98: 1134-1140. http://dx.doi.org/10.1111/ j.1365-2745.2010.01687.x

Kessler M. (2001) Pteridophyte species richness in Andean forests in Bolivia. Biodiversity \& Conservation 10: 1473-1495. http:// dx.doi.org/10.1023/a:1011811224595

Kessler M., Kluge J., Hemp A., Ohlemüller R. (2011) A global comparative analysis of elevational species richness patterns of ferns. Global Ecology and Biogeography 20: 868-880. http:// dx.doi.org/10.1111/j.1466-8238.2011.00653.x

Kichenin E., Wardle D.A., Peltzer D.A., Morse C.W., Freschet G.T. (2013) Contrasting effects of plant inter- and intraspecific variation on community-level trait measures along an environmental gradient. Functional Ecology 27: 1254-1261. http://dx.doi. org/10.1111/1365-2435.12116

Kleyer M., Dray S., Bello F., Lepš J., Pakeman R.J., Strauss B., Thuiller W., Lavorel S. (2012) Assessing species and community functional responses to environmental gradients: which multivariate methods? Journal of Vegetation Science 23: 805-821. http://dx.doi.org/10.1111/j.1654-1103.2012.01402.x

Kluge J., Kessler M. (2011) Phylogenetic diversity, trait diversity, and niches: species assembly of ferns along a tropical elevational gradient. Journal of Biogeography 38: 394-405. http://dx.doi. org/10.1111/j.1365-2699.2010.02433.x

Körner C. (1989) The nutritional status of plants from high altitudes: a worldwide comparison. Oecologia 81: 379-391. http:// dx.doi.org/10.1007/BF00377088

Körner C. (2007) The use of 'altitude' in ecological research. Trends in Ecology and Evolution 22: 569-574. http://dx.doi. org/10.1016/j.tree.2007.09.006

Lawlor D., Cornic G. (2002) Photosynthetic carbon assimilation and associated metabolism in relation to water deficits in higher plants. Plant, Cell \& Environment 25: 275-294. http://dx.doi. org/10.1046/j.0016-8025.2001.00814.x

Lebrija-Trejos E., Pérez-García E.A., Meave J.A., Bongers F., Poorter L. (2010) Functional traits and environmental filtering 
drive community assembly in a species-rich tropical system. Ecology 91: 386-398. http://dx.doi.org/10.1890/08-1449.1

Lecerf A., Chauvet E. (2008) Intraspecific variability in leaf traits strongly affects alder leaf decomposition in a stream. Basic and Applied Ecology 9: 598-605. http://dx.doi.org/10.1016/j. baae.2007.11.003

Legner N., Fleck S., Leuschner C. (2014) Within-canopy variation in photosynthetic capacity, SLA and foliar $\mathrm{N}$ in temperate broad-leaved trees with contrasting shade tolerance. Trees Structure and Function 28: 263-280. http://dx.doi.org/10.1007/ s00468-013-0947-0

Leingärtner A., Krauss J., Steffan-Dewenter I. (2014) Species richness and trait composition of butterfly assemblages change along an altitudinal gradient. Oecologia 175: 613-623. http:// dx.doi.org/10.1007/s00442-014-2917-7

Letten A.D., Ashcroft M.B., Keith D.A., Gollan J.R., Ramp D. (2013) The importance of temporal climate variability for spatial patterns in plant diversity. Ecography 36: 1341-1349. http:// dx.doi.org/10.1111/j.1600-0587.2013.00346.x

Li Z., Zheng F.-L., Liu W.-Z., Flanagan D.C. (2010) Spatial distribution and temporal trends of extreme temperature and precipitation events on the Loess Plateau of China during 19612007. Quaternary International 226: 92-100. http://dx.doi. org/10.1016/j.quaint.2010.03.003

Litchman E., Klausmeier C.A., Schofield O.M., Falkowski P.G. (2007) The role of functional traits and trade-offs in structuring phytoplankton communities: scaling from cellular to ecosystem level. Ecology letters 10: 1170-1181. http://dx.doi.org/10.1111/ j.1461-0248.2007.01117.x

Marteinsdóttir B., Eriksson O. (2014) Plant community assembly in semi-natural grasslands and ex-arable fields: a trait-based approach. Journal of Vegetation Science 25: 77-87. http://dx.doi. org/10.1111/jvs. 12058

Matesanz S., Gianoli E., Valladares F. (2010) Global change and the evolution of phenotypic plasticity in plants. Annals of the New York Academy of Sciences 1206: 35-55. http://dx.doi. org/10.1111/j.1749-6632.2010.05704.x

McCain C.M. (2007) Could temperature and water availability drive elevational species richness patterns? A global case study for bats. Global Ecology and Biogeography 16: 1-13. http:// dx.doi.org/10.1111/j.1466-8238.2006.00263.x

McGill B.J., Enquist B.J., Weiher E., Westoby M. (2006) Rebuilding community ecology from functional traits. Trends in Ecology \& Evolution 21: 178-185. http://dx.doi.org/10.1016/j. tree.2006.02.002

Messier J., McGill B.J., Lechowicz M.J. (2010) How do traits vary across ecological scales? A case for trait-based ecology. Ecology letters 13: 838-848. http://dx.doi.org/10.1111/j.14610248.2010.01476.x

Molinari N.A., D’Antonio C.M. (2014) Structural, compositional and trait differences between native- and non-native-dominated grassland patches. Functional Ecology 28: 745-754. http:// dx.doi.org/10.1111/1365-2435.12206

Mooney H.A., Dunn E.L. (1970) Convergent evolution of Mediterranean-climate evergreen sclerophyll shrubs. Evolution 24 292-303. http://dx.doi.org/10.2307/2406805

Naeem S., Wright J.P. (2003) Disentangling biodiversity effects on ecosystem functioning: deriving solutions to a seemingly insurmountable problem. Ecology Letters 6: 567-579. http://dx.doi. org/10.1046/j.1461-0248.2003.00471.x
Nelson D.W., Sommers L.E. (1974) A rapid and accurate procedure for estimating organic carbon in soil. Proceedings of the Indiana Academy of Science 84: 456-462.

Obolewski K., Strzelczak A., Glińska-Lewczuk K. (2014) Does hydrological connectivity affect the composition of macroinvertebrates on Stratiotes aloides L. in oxbow lakes? Ecological Engineering 66: 72-81. http://dx.doi.org/10.1016/j.ecoleng.2013.05.009

Palta J., Li P. (1979) Frost-hardiness in relation to leaf anatomy and natural distribution of several Solanum species. Crop Science 19: 665-671. http://dx.doi.org/10.2135/cropsci1979.0011183X $00190005003 \overline{1 x}$

Parkhurst D.F., Loucks O. (1972) Optimal leaf size in relation to environment. Journal of Ecology 60: 505-537. http://dx.doi. org $/ 10.2307 / 2258359$

Poorter L., Wright S.J., Paz H., Ackerly D., Condit R., Ibarra-Manríquez G., Harms K.E., Licona J.C., Martínez-Ramos M., Mazer S.J., Muller-Landau C., Peña-Claros M., Webb C.O., Wright I.J. (2008) Are functional traits good predictors of demographic rates? Evidence from five neotropical forests. Ecology 89: 1908-1920. http://dx.doi.org/10.1890/07-0207.1

Rapp J.M., Silman M.R., Clark J.S., Girardin C.A.J., Galiano D., Tito R. (2012) Intra- and interspecific tree growth across a long altitudinal gradient in the Peruvian Andes. Ecology 93: 20612072. http://dx.doi.org/10.1890/11-1725.1

R Core Team (2012) R: A language and environment for statistical computing. Vienna, R Foundation for Statistical Computing.

Renaut J., Lutts S., Hoffmann L., Hausman J.-F. (2004) Responses of poplar to chilling temperatures: proteomic and physiological aspects. Plant Biology 6: 81-90. http://dx.doi. org:/10.1055/s-2004-815733

Richardson A., Ashton P., Berlyn G., McGroddy M., Cameron I. (2001) Within-crown foliar plasticity of western hemlock, Tsuga heterophylla, in relation to stand age. Annals of Botany 88: 1007-1015. http://dx.doi.org/10.1006/anbo.2001.1538

Roberts M.R. (2004) Response of the herbaceous layer to natural disturbance in North American forests. Canadian Journal of Botany 82: 1273-1283. http://dx.doi.org/10.1139/B04-091

Shirke P.A., Pathre U.V. (2004) Influence of leaf-to-air vapour pressure deficit (VPD) on the biochemistry and physiology of photosynthesis in Prosopis juliflora. Journal of Experimental Botany 55: 2111-2120. http://dx.doi.org/10.1093/jxb/erh229

Ter Steege H. (1996) Winphot 5: A programme to analyze vegetation indices, light and light quality from hemispherical photographs. Tropenbos-Guyana, Programme Tropenbos.

Tilman D. (2000) Causes, consequences and ethics of biodiversity. Nature 405: 208-211. http://dx.doi.org/10.1038/35012217

Wright S.J., Kitajima K., Kraft N.J.B., Reich P.B., Wright I.J., Bunker D.E., Condit R., Dalling J.W., Davies S.J., Díaz S., Engelbrecht B.M.J., Harms K.E., Hubbell S.P., Marks C.O., RuizJaen M.C., Salvador C.M., Zanne A.E. (2010) Functional traits and the growth-mortality trade-off in tropical trees. Ecology 91: 3664-3674. http://dx.doi.org/10.1890/09-2335.1

Manuscript received 16 Apr. 2015; accepted in revised version 7 Jul. 2015.

Communicating Editor: Pierre Meerts. 